\title{
Introduction of Solid Food to Young Infants
}

\author{
Alice A. Kuo • Moira Inkelas • Wendelin M. Slusser • \\ Molly Maidenberg $\cdot$ Neal Halfon
}

Published online: 15 September 2010

(c) The Author(s) 2010. This article is published with open access at Springerlink.com

\begin{abstract}
Timing of the first introduction of solid food during infancy may have potential effects on life-long health. To understand the characteristics that are associated with the timing of infants' initial exposure to solid foods. The 2000 National Survey of Early Childhood Health (NSECH) was a nationally representative telephone survey of 2,068 parents of children aged 4-35 months, which profiled content and quality of health care for young children. African-American and Latino families were oversampled. Analyses in this report include bivariate tests and logistic regressions. $62 \%$ of parents reported introducing solids to their child between 4-6 months of age. AfricanAmerican mothers $(\mathrm{OR}=0.5[0.3,0.9])$, English-speaking Latino mothers $(\mathrm{OR}=0.4[0.2,0.7])$, White mothers with more than high school education $(\mathrm{OR}=0.5[0.2,1.0])$, and mothers who breastfed for 4 months or longer $(\mathrm{OR}=0.4$ $[0.3,0.7])$ were less likely to introduce solids early. Most parents (92\%) of children 4-9 months of age reported that their pediatric provider had discussed introduction of solids with them since the child's birth, and provider discussion of feeding was not associated with the timing of introduction of solids. Although most parents recall discussing
\end{abstract}

\footnotetext{
A. A. Kuo $(\varangle) \cdot$ W. M. Slusser · M. Maidenberg - N. Halfon Department of Pediatrics, David Geffen School of Medicine at UCLA, UCLA Center for Healthier Children, Families and Communities, 10990 Wilshire Blvd., Suite 900, Los Angeles, CA, USA

e-mail: akuo@mednet.ucla.edu
}

\section{A. A. Kuo $\cdot$ M. Inkelas $\cdot$ N. Halfon}

Department of Health Services, UCLA School of Public Health, Los Angeles, USA

W. M. Slusser

Department of Community Health Sciences, UCLA School of Public Health, Los Angeles, USA the introduction of solid foods with their child's physician, several subgroups of mothers introduce solid foods earlier than the AAP recommendation of 4-6 months. More effective discussion of solid food introduction linked to counseling and support of breastfeeding by the primary health care provider may reduce early introduction of solids.

Keywords Early feeding - Breastfeeding - Introduction of solid foods

\section{Introduction}

Timing of the first introduction of solid food during infancy is an important area of pediatric health supervision due to its potential effects on life-long health [1, 2]. Child feeding practices are successful when the food provided meets the nutritional needs of the infant, protects the airway against aspiration of foreign food substances, and does not exceed the functional capacity of the gastrointestinal tract and the kidneys [3]. A "sensitive" or "critical" period for the timing of the introduction of solid foods has been hypothesized, but there is no evidence that introduction of solid foods during the sensitive periods influences children's later acceptance of food [4]. Some studies suggest that introducing solid foods too early may lead to increased risk of chronic disease such as islet autoimmunity (the preclinical condition leading to type 1 diabetes), obesity, adult-onset celiac disease, and eczema; and introduction too late may increase feeding difficulties [5-8]. In addition, early introduction to solid foods may lead to poor nutrition outcomes such as low iron stores by displacing energy rich and highly bioavailable iron in breastmilk, and increasing the risk of diarrheal disease $[9,10]$. 
Recent studies have demonstrated the important of early feeding — both timing and amount—in the development of metabolic problems in adulthood [11, 12]. Cotrell and Ozanne describe the programming for obesity and adult metabolic diseases such as hypertension, diabetes, and coronary artery diseases as possibly resulting from both underfeeding and overfeeding in early infancy [12]. The increased focus on understanding feeding patterns as a precursor to obesity makes the timing of the first introduction of solid food an important issue to examine.

The American Academy of Pediatrics (AAP) recommends exclusive breastfeeding for the first 6 months of life, in part to delay the introduction of solid foods until 6 months of age because breastmilk provides all of the nutritional requirements for the growing infant during the first 6 months of life [13]. Introducing solid foods after the recommended 6 months of age is also not optimal because it may cause deficiencies of zinc, protein, iron, and vitamins $\mathrm{B}$ and $\mathrm{D}$ that in turn suppress growth, and cause feeding problems [9]. Building on prior recommendations for the timing of the introduction of solids [9, 14], a 2005 American Academy of Pediatrics (AAP) policy statement by the Section on Breastfeeding encouraged delaying the introduction of solid foods (including cereal) until a child is 6 months of age for exclusively breastfed infants and 4-6 months for infants who are formula-fed [13].

Advice from pediatric clinicians related to introduction to solid foods can influence when parents introduce solids because there are multiple opportunities of contact with the parents during an infant's first month of life. The WIC program is another major source of nutrition information for parents of young children in households at or below $185 \%$ Federal Poverty Level (FPL); WIC serves more than 8 million parents of infants each month [15]. Receiving professional advice has been shown to influence parents' breastfeeding initiation [16], and parents report valuing pediatric advice during early childhood [17]. Understanding patterns of professional advice is important because prior studies suggest that the timing of the introduction of solid foods is associated with family factors including maternal ethnicity, cultural beliefs, education, breastfeeding status and duration, participation in the Supplementary Nutrition Program for Women, Infants and Children (WIC), and also whether a provider discussion of the introduction of solid foods had occurred [3, 18, 19].

Despite professional recommendations, national studies indicate that many parents are not following these guidelines. The 1988-1994 National Health and Nutrition Examination Survey (NHANES III) showed that $25 \%$ of parents reported introducing solid foods prior to age 4 months, including about half $(53 \%)$ of formula-fed infants and $29 \%$ of the non-exclusively breastfed infants [20]. In a nationally representative sample of infants and toddlers ages 4-24 months, Hendricks et al. found that about one-third of parents introduced solids prior to age 4 months and that more children with early introduction of complementary foods were African-American, living in households below 185\% FPL, having a younger mother (in years), having married parents, and not receiving WIC [21]. In addition, introduction of complementary foods prior to age 4 months was associated with the mother having less than a college education, younger maternal age, the child not being first born, and never breastfeeding the child, but was not associated with race/ethnicity, marital status or use of WIC [21].

Given the nutritional, allergic, developmental, and chronic disease risks associated with introducing solid foods early or late, it is important to understand national patterns of child and family factors that are associated with either early or late introduction of solid foods and learn potential opportunities to modify factors to optimize the timing of the introduction of solid foods in infancy. This study uses the nationally representative National Survey of Early Childhood Health (NSECH) sample to determine factors associated with early or late introduction of solids, with particular emphasis on racial/ethnic differences and potential differences within these subgroups associated with factors such as maternal education. Knowledge of these differences is a key first step for the formulation of effective interventions for improving the rates of introduction of solid foods within the optimal time period.

\section{Methods}

The National Survey of Early Childhood Health (NSECH) is a telephone survey of a national random sample of 2,068 parents of children between ages 4 and 35 months conducted by the National Center for Health Statistics (NCHS) in 2000 [22]. Structured telephone interviews of approximately 30 min were conducted in English or Spanish with parents, and questions addressed the content and quality of early childhood health care. African-American and Latino children were oversampled to provide a nationally representative sample of underrepresented populations suitable for subgroup analyses. Eighty-seven percent of the respondents are mothers of the sampled child. The remaining are fathers $(11 \%)$, grandparents $(2 \%)$, or other guardians $(<1 \%)$. The CASRO response rate was $65.6 \%$. Weighting adjusted for unit non-response, estimated non-response for households with no telephones or multiple telephones, multiple eligible children in a household, over-sampling, and post-stratification to match population control estimates from Census data. A more complete description of the NSECH is presented elsewhere [22]. 


\section{Measures}

The survey asked parents "How old was (CHILD) when you introduced solid foods? When I say solid foods here I mean anything other than milk, formula or juice." The child's age at introduction of solids was categorized as occurring between 0-3 months, 4-6 months, 7-9 months, or after 9 months. A total of 2,020 survey participants answered this question, while 25 had not yet introduced solids at the time of survey, 22 did not know, and one refused to answer the question. For Table 3 and the logistic regression models of Table 4, only participants who reported introduction between 0-9 months were included in the analysis ( $N=1,894)$ due to concerns that those reporting very late introduction (after 9 months) may have misunderstood the question. Results were essentially unchanged when the very late introduction group $(N=126)$ was included in the regression analyses.

Based on the question, "Was (CHILD) breastfed for any length of time?" children were classified as being breastfed for 1 month or less, for 2 or 3 months, for 4 months through 7 months, or for more than 8 months. Based on bivariate findings this variable was further collapsed for multivariate analysis into never breastfed, breastfed for fewer than 4 months, and breastfed for four or more months. WIC program participation was dichotomized as a yes or no parent response of ever having received WIC for the child. Mothers were categorized as "Latino" if Latino ethnicity of the mother was reported, regardless of race. Latinos were further subdivided according to whether they were interviewed in English or Spanish. Children with mother's race/ ethnicity classified as "Other" or unknown $(N=72)$ were omitted from the regression analyses; however, these children are included in the "All" column of Table 1.

The question, "Since (CHILD)'s birth, did (his/her) doctors or health providers talk with you about issues related to food or feeding (his/her) such as the introduction of solid foods?," was asked only for those children under 10 months $(N=431)$, and was used as a dichotomous measure representing whether provider discussion occurred or not.

\section{Statistical Analyses}

All frequencies in Tables 2 and 3 were calculated as weighted sample or subsample estimates. Significance tests for Table 2 were computed using a Rao-Scott statistic, which is the Pearson $\chi^{2}$ test for contingency tables adjusted for the survey design [23, 24]. Table 4 was produced using weighted logistic regressions with standard error estimates adjusted for the sampling design through a first-order Taylor series approximation, and significance tests were performed using design-adjusted Wald tests [25]. All analyses were conducted using the Stata statistical software package, version 8.2 [26].

\section{Results}

Table 1 presents demographic information and other sample characteristics by maternal race/ethnicity. White mothers (median age 30 years) were older than mothers of other ethnicities (median age of nonwhites 26 years). The African-American and Latino English subgroups had more young mothers; about $20 \%$ of mothers in these groups were aged 17-20 years, whereas fewer than $10 \%$ of mothers in the White and Latino Spanish subgroups were in this age group.

Maternal education showed considerable differences by the race, ethnicity, and language groups (Table 1). Latino Spanish-speaking mothers had far less education than the other groups, followed by Latino English-speaking and African-American mothers (who had similar levels of education). Income also varied in a similar manner. About a third of families with African-American mothers and $20 \%$ of families with Latino English-speaking mothers had only a single adult in the household. In contrast, fewer than $6 \%$ of families with white or Latino Spanish-speaking mothers had only a single adult in the household.

Breastfeeding initiation was greatest among Latino Spanish-speaking mothers (over $80 \%$ ) followed by White and Latino English-speaking mothers (about 70\%) and African-American mothers (46\%). Duration of breastfeeding was similar among African-American and Latino English-speaking mothers and higher for white and Latino Spanish-speaking mothers. WIC participation was much higher in non-whites (over 70\%) than whites (39\%).

Table 2 shows age of introduction of solid foods. Overall, $62 \%$ of parents reported introducing solids to their child within the recommended 4-6 month age window. About $19 \%$ of all children started solids prior to 4 months of age and about $19 \%$ started at 7 months of age or later. Associations of measures are provided for early introduction (0-3 months) compared to introduction within the recommended window (4-6 months), and late introduction (7-9 months) compared to introduction within the recommended window. Lower maternal education, having only one adult in the household, never breastfeeding for any period, breastfeeding for a shorter duration, and ever participating in WIC was associated with introducing solids early rather than within the 4-6 month window. Late introduction of solids (7-9 months) was associated with African-American, maternal race/ethnicity, maternal educational attainment of high school or less than high school, having one rather than two adults in the household, and low birthweight. 
Table 1 NSECH demographic and other sample characteristics by mother's race/ethnicity and language of interview (if Latino)
${ }^{a}$ Includes $N=72(5.0 \%)$ of subjects with mother's race/ ethnicity classified as "Other"

\begin{tabular}{|c|c|c|c|c|c|}
\hline & White & $\begin{array}{l}\text { African- } \\
\text { American }\end{array}$ & $\begin{array}{l}\text { Latino } \\
\text { English }\end{array}$ & $\begin{array}{l}\text { Latino } \\
\text { Spanish }\end{array}$ & $\mathrm{All}^{\mathrm{a}}$ \\
\hline Sample $(N)$ & 818 & 440 & 331 & 397 & 2068 \\
\hline Weighted sample (\%) & 63.1 & 14.1 & 7.8 & 10.0 & 100.0 \\
\hline \multicolumn{6}{|l|}{ Mother's age (year) } \\
\hline $17-20$ & 7.3 & 21.9 & 19.0 & 9.8 & 10.6 \\
\hline $21-25$ & 19.1 & 25.1 & 30.3 & 33.3 & 22.6 \\
\hline $26-30$ & 26.9 & 26.4 & 25.0 & 26.9 & 26.6 \\
\hline $31-35$ & 26.2 & 15.8 & 16.8 & 22.0 & 23.5 \\
\hline$\geq 36$ & 20.5 & 10.8 & 8.9 & 8.1 & 16.6 \\
\hline \multicolumn{6}{|l|}{ Mother's education } \\
\hline Less than high school graduate & 10.1 & 26.3 & 33.9 & 67.0 & 20.6 \\
\hline High school graduate & 34.9 & 39.8 & 37.1 & 21.9 & 33.8 \\
\hline More than high school & 55.0 & 33.9 & 28.9 & 11.1 & 45.6 \\
\hline \multicolumn{6}{|l|}{ Mother's employment status } \\
\hline Full-time & 33.1 & 45.4 & 34.4 & 27.9 & 34.7 \\
\hline Part-time & 22.5 & 15.4 & 16.0 & 13.5 & 19.5 \\
\hline Not employed & 44.4 & 39.3 & 49.6 & 58.6 & 45.8 \\
\hline \multicolumn{6}{|l|}{ Household income (\$) } \\
\hline$\leq 7,500$ & 3.6 & 16.3 & 9.1 & 15.7 & 7.4 \\
\hline $7,501-17,500$ & 10.1 & 32.4 & 28.2 & 44.0 & 17.6 \\
\hline $17,501-35,000$ & 27.9 & 27.7 & 29.6 & 35.2 & 28.7 \\
\hline $35,001-60,000$ & 28.8 & 13.1 & 20.9 & 4.1 & 23.0 \\
\hline$>60,000$ & 29.6 & 10.5 & 12.2 & 1.0 & 23.3 \\
\hline \multicolumn{6}{|l|}{ Number of adults in household } \\
\hline 1 & 5.6 & 32.9 & 19.1 & 4.2 & 10.4 \\
\hline$>1$ & 94.4 & 67.1 & 80.9 & 95.8 & 89.6 \\
\hline \multicolumn{6}{|l|}{ Number of children in household } \\
\hline 1 & 30.7 & 25.6 & 27.6 & 23.9 & 29.7 \\
\hline$>1$ & 69.3 & 74.4 & 72.4 & 76.1 & 70.3 \\
\hline \multicolumn{6}{|l|}{ Birthweight (g) } \\
\hline$<2,500$ & 8.2 & 12.5 & 8.1 & 4.9 & 8.3 \\
\hline$\geq 2,500$ & 91.8 & 87.5 & 91.9 & 95.1 & 91.7 \\
\hline \multicolumn{6}{|l|}{ Breastfeeding for any period } \\
\hline Yes & 68.7 & 46.0 & 68.5 & 82.8 & 67.3 \\
\hline No & 31.3 & 54.0 & 31.5 & 17.2 & 32.7 \\
\hline \multicolumn{6}{|c|}{ Breastfeeding duration if ever breastfed (months) } \\
\hline$\leq 1$ & 33.9 & 49.6 & 46.4 & 36.4 & 36.6 \\
\hline $2-3$ & 16.3 & 17.4 & 24.3 & 18.5 & 18.2 \\
\hline $4-7$ & 23.9 & 21.7 & 17.7 & 25.9 & 23.0 \\
\hline$\geq 8$ & 25.8 & 11.4 & 11.6 & 19.3 & 22.2 \\
\hline \multicolumn{6}{|l|}{ WIC program participation, ever } \\
\hline Yes & 38.8 & 85.4 & 72.0 & 85.1 & 52.8 \\
\hline No & 61.2 & 14.6 & 28.0 & 14.9 & 47.2 \\
\hline
\end{tabular}

Table 3 shows age of introduction of solid foods by race, ethnicity, and language for mothers with different levels of education. For mothers with a less than high school graduate education, the lowest rates of introduction of solids during the 4-6 month window were seen among whites (47\%) and African-Americans (40\%). Englishspeaking Latino (58\%) and Spanish-speaking Latino (66\%) mothers had considerably higher rates of introduction during the 4-6 month window. African-American mothers with a less than high school graduate education had the 
Table 2 Reported age of introduction of solid foods by maternal and household factors

\begin{tabular}{|c|c|c|c|c|c|c|}
\hline & \multicolumn{4}{|c|}{$\begin{array}{l}\text { Age of child at introduction } \\
\text { of solid foods }\end{array}$} & \multicolumn{2}{|c|}{$\begin{array}{l}\text { Association of factor } \\
\text { with solid foods introduction }\end{array}$} \\
\hline & $\begin{array}{l}0-3 \\
\text { Months } \\
(\%)\end{array}$ & $\begin{array}{l}4-6 \\
\text { Months } \\
(\%)\end{array}$ & $\begin{array}{l}7-9 \\
\text { Months } \\
(\%)\end{array}$ & $\begin{array}{l}\geq 10 \\
\text { Months } \\
(\%)\end{array}$ & $\begin{array}{l}\text { Before } \\
4 \text { months (vs. } \\
4-6 \text { months) }\end{array}$ & $\begin{array}{l}\text { After } \\
6 \text { months (vs. } \\
4-6 \text { months) }\end{array}$ \\
\hline Total & 18.8 & 61.9 & 12.2 & 7.1 & & \\
\hline Mother's age (year) & & & & & NS & NS \\
\hline $17-20$ & 16.9 & 57.2 & 18.3 & 7.6 & & \\
\hline $21-25$ & 23.8 & 56.0 & 11.0 & 9.2 & & \\
\hline $26-30$ & 19.4 & 60.4 & 11.8 & 8.4 & & \\
\hline $31-35$ & 18.3 & 68.4 & 9.8 & 3.5 & & \\
\hline$\geq 36$ & 12.9 & 65.8 & 14.4 & 6.9 & & \\
\hline Mother's education & & & & & $*$ & $* *$ \\
\hline Less than high school graduate & 19.1 & 55.1 & 17.7 & 8.1 & & \\
\hline High school graduate & 22.2 & 57.6 & 12.3 & 8.0 & & \\
\hline More than high school & 16.0 & 68.3 & 9.7 & 6.0 & & \\
\hline Mother's race/ethnicity/language & & & & & NS & $* *$ \\
\hline White & 20.6 & 63.0 & 10.3 & 6.1 & & \\
\hline African-American & 16.5 & 49.5 & 20.2 & 13.8 & & \\
\hline Latino, English & 14.6 & 61.3 & 16.1 & 8.1 & & \\
\hline Latino, Spanish & 16.1 & 69.1 & 9.5 & 5.3 & & \\
\hline Other & 14.9 & 66.5 & 14.9 & 3.7 & & \\
\hline Mother's employment & & & & & NS & NS \\
\hline Full-time & 21.6 & 57.5 & 13.9 & 7.0 & & \\
\hline Part-time & 16.2 & 69.5 & 11.5 & 2.9 & & \\
\hline Not employed & 17.8 & 62.2 & 11.2 & 8.9 & & \\
\hline Household income (\$) & & & & & NS & NS \\
\hline$\leq 7,500$ & 20.9 & 61.3 & 10.7 & 7.1 & & \\
\hline $7,501-17,500$ & 16.2 & 55.6 & 14.3 & 13.9 & & \\
\hline $17,501-35,000$ & 22.4 & 59.4 & 11.7 & 6.6 & & \\
\hline $35,001-60,000$ & 20.1 & 62.4 & 12.7 & 4.8 & & \\
\hline$>60,000$ & 14.0 & 68.4 & 13.7 & 4.0 & & \\
\hline Number of adults in household & & & & & $* *$ & $*$ \\
\hline 1 & 24.8 & 46.3 & 15.7 & 13.2 & & \\
\hline$>1$ & 18.0 & 63.8 & 11.8 & 6.4 & & \\
\hline Number of children in household & & & & & NS & NS \\
\hline 1 & 16.7 & 64.6 & 13.3 & 5.4 & & \\
\hline$>1$ & 19.6 & 60.8 & 11.8 & 7.8 & & \\
\hline Birthweight (g) & & & & & NS & $*$ \\
\hline$<2,500$ & 14.9 & 54.5 & 21.6 & 9.1 & & \\
\hline$\geq 2,500$ & 19.3 & 62.2 & 11.6 & 7.0 & & \\
\hline Breastfeeding for any period & & & & & $* * *$ & NS \\
\hline Yes & 16.4 & 66.2 & 12.2 & 5.3 & & \\
\hline No & 23.7 & 53.3 & 12.2 & 10.9 & & \\
\hline Breastfeeding duration if ever breastfed & & & & & $* * *$ & NS \\
\hline$\leq 1$ & 24.3 & 61.4 & 10.4 & 3.9 & & \\
\hline $2-3$ & 19.9 & 65.0 & 12.5 & 2.6 & & \\
\hline $4-7$ & 9.7 & 66.7 & 17.6 & 6.0 & & \\
\hline$\geq 8$ & 8.7 & 69.9 & 11.9 & 9.4 & & \\
\hline WIC program participation, ever & & & & & $*$ & NS \\
\hline Yes & 20.7 & 56.7 & 12.9 & 9.7 & & \\
\hline No & 16.4 & 68.2 & 11.6 & 3.8 & & \\
\hline
\end{tabular}

NS Not significant $(P \geq 0.05)$

$* P<0.05$, ** $P<0.01$,

*** $P<0.001$
Age of child at introduction

Months Months Months Months

$\begin{array}{llll}16.9 & 57.2 & 18.3 & 7.6\end{array}$

$\begin{array}{llll}23.8 & 56.0 & 11.0 & 9.2\end{array}$

$\begin{array}{llll}19.4 & 60.4 & 11.8 & 8.4\end{array}$

$\begin{array}{llll}18.3 & 68.4 & 9.8 & 3.5\end{array}$

$\begin{array}{llll}12.9 & 65.8 & 14.4 & 6.9\end{array}$

$\begin{array}{llll}19.1 & 55.1 & 17.7 & 8.1\end{array}$

$22.2 \quad 57.6 \quad 12.3 \quad 8.0$

$\begin{array}{llll}16.0 & 68.3 & 9.7 & 6.0\end{array}$

$\begin{array}{llll}20.6 & 63.0 & 10.3 & 6.1\end{array}$

$\begin{array}{lll}16.5 & -49.5 & 20.2-13.8\end{array}$

$\begin{array}{lll}61.3 & 16.1 & 8.1\end{array}$

$\begin{array}{llll}16.1 & 69.1 & 9.5 & 5.3\end{array}$

$\begin{array}{llll}4.9 & 66.5 & 14.9 & 3.7\end{array}$

$\begin{array}{llll}21.6 & 57.5 & 13.9 & 7.0\end{array}$

$\begin{array}{llll}16.2 & 69.5 & 11.5 & 2.9\end{array}$

$\begin{array}{llll}17.8 & 62.2 & 11.2 & 8.9\end{array}$

$\begin{array}{llll}20.9 & 61.3 & 10.7 & 7 .\end{array}$

$\begin{array}{llll}16.2 & 55.6 & 14.3 & 13.9\end{array}$

$59.4 \quad 11.7$

$\begin{array}{lll}62.4 & 12.7 & 4.8\end{array}$

$\begin{array}{llll}14.0 & 68.4 & 13.7 & 4.0\end{array}$

$\begin{array}{llll}24.8 & 46.3 & 15.7 & 13.2\end{array}$

$\begin{array}{llll}16.7 & 64.6 & 13.3 & 5.4\end{array}$

$14.9 \quad 54.5 \quad 21.6 \quad 9.1$

$\begin{array}{llll}16.4 & 66.2 & 12.2 & 5.3\end{array}$

$\begin{array}{llll}23.7 & 53.3 & 12.2 & 10.9\end{array}$

$\begin{array}{llll}24.3 & 61.4 & 10.4 & 3.9\end{array}$

$\begin{array}{llll}19.9 & 65.0 & 12.5 & 2.6\end{array}$

$\begin{array}{llll}9.7 & 66.7 & 17.6 & 6.0\end{array}$

$\begin{array}{llll}8.7 & 69.9 & 11.9 & 9.4\end{array}$

$\begin{array}{llll}20.7 & 56.7 & 12.9 & 9.7\end{array}$ 
Table 3 Introduction of solid foods for mothers with education of less than high school, high school, or more than high school

\begin{tabular}{|c|c|c|c|c|}
\hline Education & $\begin{array}{l}\text { Ethnicity/ } \\
\text { language }\end{array}$ & $\begin{array}{l}0-3 \\
\text { Months (\%) }\end{array}$ & $\begin{array}{l}4-6 \\
\text { Months (\%) }\end{array}$ & $\begin{array}{l}7-9 \\
\text { Months (\%) }\end{array}$ \\
\hline \multirow[t]{5}{*}{ Less than high school graduate } & White & 28 & 48 & 18 \\
\hline & Black & 10 & 40 & 30 \\
\hline & Latino English & 18 & 58 & 22 \\
\hline & Latino Spanish & 17 & 66 & 11 \\
\hline & Other & 14 & 72 & 9 \\
\hline \multirow[t]{5}{*}{ High school graduate } & White & 26 & 57 & 10 \\
\hline & Black & 17 & 52 & 20 \\
\hline & Latino English & 13 & 53 & 19 \\
\hline & Latino Spanish & 11 & 79 & 7 \\
\hline & Other & 17 & 70 & 11 \\
\hline \multirow[t]{5}{*}{ More than high school } & White & 16 & 70 & 9 \\
\hline & Black & 22 & 54 & 13 \\
\hline & Latino English & 13 & 76 & 5 \\
\hline & Latino Spanish & 20 & 67 & 8 \\
\hline & Other & 14 & 63 & 19 \\
\hline
\end{tabular}

lowest rate of early introduction (0-3 months, 10\%) and the highest rate of late introduction (7-9 months, 30\%). White mothers with a less than a high school education had the highest rate of early introduction (28\%).

Comparison of education levels in Table 3 for Spanishspeaking Latino mothers show little association of education level with the timing of the introduction of solids. Spanish-speaking Latino mothers have high rates of introduction during the 4-6 month window and low rates of late introduction regardless of their level of education. In contrast, level of education was associated with timing of solids among white mothers with increasing rates of introduction during the 4-6 month window as the level of education increases (57\% for high school graduates and $70 \%$ for mothers with more than high school). The level of education also was associated with the timing of introduction of solids for African-American mothers, especially their rates of late introduction (7-9 months), which drop considerably as education increases (late introduction rates are $20 \%$ for high school graduates and $13 \%$ for mothers with more than high school). English-speaking Latino mothers who are high school graduates had a pattern of introduction that was very similar to that of Englishspeaking Latino mothers who had a less than high school graduate education (Table 3a). However, English-speaking Latino mothers with more than a high school education (Table 3c) had much higher rates of introduction during the 4-6 month window (76\%) and lower rates of late introduction (5\%) than English-speaking Latino mothers with less education.

Table 4 presents results from two multivariate logistic regressions: the first modeling early introduction versus introduction in the 4-6 month window and the second modeling late introduction versus introduction 4-6 months. Odds of introducing solids early rather than in the recommended window of 4-6 months were higher for households with only one adult $(\mathrm{OR}=2.0[1.1,3.6])$ and significantly lower for English-speaking Latino mothers $(\mathrm{OR}=0.4$ $[0.2,0.7])$ and African-American mothers $(\mathrm{OR}=0.5[0.3$, 0.9]) relative to white mothers. Mothers who breastfed for 4 months or longer were less likely to introduce solids early $(\mathrm{OR}=0.4[0.3,0.7])$.

In these multivariate analyses, there was no association between education and early introduction of solids for African-American, English-speaking Latino, or Spanishspeaking Latino mothers. Education was only associated with timing for white mothers: white mothers with more than a high school education had lower rates of early introduction than other white mothers $(\mathrm{OR}=0.5[0.2$, 1.0]). This association is shown in the first model of Table 2 as an interaction between education and race. This confirms the results of Table 3 , which show that education had a greater effect for white mothers on the early introduction of solids than for African-American and Latino mothers. The logistic model in Table 2 showed no significant association between WIC participation and the early introduction of solids, in contrast to the significant bivariate association between WIC participation and early introduction displayed in Table 1. Stratified analyses (data not shown) indicated that the unadjusted bivariate WIC association may result from confounding with single adult household status and breastfeeding.

Odds of late introduction of solids were significantly higher for African-American mothers $(\mathrm{OR}=2.4$ [1.4, 4.1]) and significantly lower for Spanish-speaking Latino mothers $(\mathrm{OR}=0.5[0.2,1.0])$ relative to white mothers. 
Table 4 Odds ratios (with $95 \%$ confidence intervals) from logistic regressions of age of introduction of solid foods: 0-3 months versus 4-6 months ( $\geq 7$ months excluded) and 7-9 months vs. 4-6 months (0-3 months and $\geq 10$ months excluded)

\begin{tabular}{|c|c|c|}
\hline & $\begin{array}{l}\text { Before } 4 \text { months } \\
\text { (vs. } 4-6 \text { months) }\end{array}$ & $\begin{array}{l}\text { After } 6 \text { months } \\
\text { (vs. } 4-6 \text { months) }\end{array}$ \\
\hline \multicolumn{3}{|l|}{ Mother's age (year) } \\
\hline $17-20$ & $0.9(0.4,1.7)$ & $1.1(0.4,2.9)$ \\
\hline $21-25$ & $1.6(0.9,2.6)$ & $1.0(0.6,1.7)$ \\
\hline $26-30$ & 1 & 1 \\
\hline $31-35$ & $0.8(0.5,1.4)$ & $0.5(0.3,1.0)^{*}$ \\
\hline$\geq 36$ & $0.6(0.3,1.2)$ & $1.1(0.6,2.1)$ \\
\hline \multicolumn{3}{|l|}{ Mother's education } \\
\hline Less than high school graduate & $0.8(0.4,1.5)$ & $4.8(2.2,10)^{* * *}$ \\
\hline High school graduate & $0.7(0.4,1.3)$ & $2.3(1.4,4.0)^{* *}$ \\
\hline More than high school & 1 & 1 \\
\hline White, more than high school & $0.5(0.2,1.0)^{*}$ & \\
\hline \multicolumn{3}{|l|}{ Mother's race/ethnicity/language } \\
\hline White & 1 & 1 \\
\hline African-American & $0.5(0.3,0.9)^{*}$ & $2.4(1.4,4.1)^{* *}$ \\
\hline Latino, English & $0.4(0.2,0.7)^{* *}$ & $1.2(0.7,2.2)$ \\
\hline Latino, Spanish & $0.6(0.3,1.1)$ & $0.5(0.2,1.0)^{*}$ \\
\hline \multicolumn{3}{|l|}{ Mother's employment } \\
\hline Full-time & 1 & 1 \\
\hline Part-time & $0.9(0.5,1.5)$ & $0.6(0.3,1.1)$ \\
\hline Not employed & $0.8(0.6,1.2)$ & $0.7(0.4,1.1)$ \\
\hline \multicolumn{3}{|l|}{ Household income $(\$)$} \\
\hline$\leq 7,500$ & $0.8(0.3,2.1)$ & $0.3(0.1,0.8)^{*}$ \\
\hline $7,501-17,500$ & $0.7(0.3,1.6)$ & $0.5(0.1,1.5)$ \\
\hline $17,501-35,000$ & $1.1(0.6,2.2)$ & $0.5(0.2,1.2)$ \\
\hline $35,001-60,000$ & $1.2(0.6,2.1)$ & $0.8(0.4,1.5)$ \\
\hline$>60,000$ & 1 & 1 \\
\hline \multicolumn{3}{|l|}{ Number of adults in household } \\
\hline 1 & $2.0(1.1,3.6)^{*}$ & $1.2(0.7,2.2)$ \\
\hline$>1$ & 1 & 1 \\
\hline \multicolumn{3}{|l|}{ Number of children in household } \\
\hline 1 & $0.8(0.5,1.1)$ & $1.2(0.8,1.9)$ \\
\hline$>1$ & 1 & 1 \\
\hline \multicolumn{3}{|l|}{ Birthweight (g) } \\
\hline$<2,500$ & $0.8(0.4,1.7)$ & $2.0(0.9,4.3)$ \\
\hline$\geq 2,500$ & 1 & 1 \\
\hline \multicolumn{3}{|l|}{ Breastfeeding } \\
\hline Never & 1 & 1 \\
\hline$<4$ months & $1.0(0.7,1.5)$ & $1.1(0.6,1.8)$ \\
\hline$\geq 4$ months & $0.4(0.3,0.7)^{* *}$ & $2.1(1.2,3.6)^{* *}$ \\
\hline \multicolumn{3}{|l|}{ WIC program participation, ever } \\
\hline Yes & $1.1(0.7,1.8)$ & $1.2(0.6,2.5)$ \\
\hline No & 1 & 1 \\
\hline
\end{tabular}

$* P<0.05, * * P<0.01$ *** $P<0.001$ higher for mothers with a less than high school graduate education $(\mathrm{OR}=4.8[2.2,10])$ or who were high school graduates $(\mathrm{OR}=2.3[1.4,4.0])$ compared to those with more than high school. No significant interaction was found between education and race, ethnicity, and language 
for late introduction of solids. Our analyses (Table 2 and other stratified analyses, not shown) indicated that the apparent greater effect of education on late introduction of solids for African-American mothers in Table 3 is an absolute effect, not a relative one. African-American mothers have, overall, greater rates of late introduction of solids; hence, their absolute levels change more with education, but their relative levels do not change significantly more with education than do levels for other mothers.

In contrast to the bivariate findings in Table 2, no significant association was found between late introduction of solids and the number of adults in the household or the child having low birthweight. Again, the bivariate results that are only significant in Table 1 appear due to confounding between these variables and the highly significant terms (education and race) in Table 2. Breastfeeding for 4 months or longer was associated with greater odds of late introduction $(\mathrm{OR}=2.1[1.2,3.5])$. Very low income $(\leq \$ 7,500)$ was associated with lower rates of late introduction $(\mathrm{OR}=0.3[0.1,0.8])$.

About $92 \%$ of parents of young infants (age 4-9 months at the time of the survey) reported that their pediatric provider discussed introduction of solids since the child's birth. Rate of discussion did not vary with demographic factors. Provider discussion of feeding had no significant association with the timing of the introduction of solid foods (data not shown).

\section{Discussion}

A nationally representative sample of infant feeding practices revealed specific social, demographic and behavioral factors associated with less than optimal feeding practices. These results have important implications for improving anticipatory guidance about optimal feeding practices, and for targeting interventions that might improve infant feeding behaviors. White mothers with high school education or less had the highest rates of early introduction (before 4 months of age) of solid foods relative to introduction during the recommended 4-6 months of age window. White mothers with more than high school education and non-White mothers regardless of their education had about the same rates of early introduction. After controlling for other factors, no association with early introduction of solids was seen for maternal age, employment status, income, number of children in the household, low birthweight, never breastfeeding compared to breastfeeding for less than 4 months, and WIC participation.

The greater rates of early introduction among households with only one parent suggest the potential value of targeting efforts for single head-of-household families. It is not clear if the mechanism is their single-parent status or if living in a single parent household is a marker for input from a broader social support network that influences decision-making.

As in prior studies, breastfeeding appears to protect against early introduction of solids. For exclusively breastfeeding mothers, the AAP currently recommends introduction of solids after 6 months with multivitamin supplementation. The results of our study indicate that the initiation of breastfeeding by itself is not associated with lower rates of early introduction of solid foods. Breastfeeding for fewer than 4 months is no different than never breastfeeding. Breastfeeding for 4 months or more may push introduction of solid foods to later times, thereby reducing early introduction but possibly increasing late introduction. Discussion and support of breastfeeding may positively influence the optimal timing of introduction of solid foods and is the recommendation by the AAP (2005).

Some of our results for racial and ethnic differences in early childhood feeding behaviors differ from prior studies. We found African-American mothers were more likely to introduce solids to their infants at 7 months or later but were no more likely to introduce solids earlier than 4 months. The 2002 Feeding Infant and Toddlers Survey (FITS) study also found no racial/ethnic differences in early introduction when accounting for other demographic factors [21]. One possible explanation is our study is nationally representative with an oversample of AfricanAmerican children whereas prior studies used smaller samples and focused on parents in urban, low-income households.

Overall, Spanish-speaking Latino mothers were the most likely to introduce solids during the 4-6 month window. We also found Spanish-speaking Latino mothers had the lowest rates of late introduction. This group of mothers also had the highest rates of ever breastfeeding (83\%), and of those who breastfed, $45 \%$ did so for at least 4 months. It is possible that with appropriate breastfeeding, fewer mothers perceived the need to start solid foods earlier than 4 months. English-speaking Latino mothers who are perhaps more acculturated than the Spanish-speaking Latino mothers demonstrated patterns of breastfeeding and introduction of solid foods similar to their White counterparts.

Our analysis of the interaction between education and maternal race/ethnicity suggests education has a relatively weak effect among White mothers for early introduction and a strong effect for late introduction overall. This suggests early introduction may be due to socio-cultural factors that are common among Whites with lower levels of education and among single mothers (of any race or ethnicity), whereas late introduction may be due to a lack of knowledge regarding the optimal time for introduction of 
solids. Further studies are needed to disentangle the effects of this interaction for introduction of solid foods in infants.

Given the finding that demographic subgroups of infants in the US are at greater risk of adverse health outcomes such as obesity and celiac disease [27], there is a need to identify more effective health education messaging to parents about the importance of the 4-6 month window for introduction of solid foods. Prior ethnographic studies suggesting culture, intergenerational factors, peer advice, and receiving free samples of manufactured food may all influence the timing of solid food introduction [28, 29]; therefore, addressing these specific influences within health education may be needed. Crocetti et al. found in a small clinical sample that $76 \%$ of parents who started solids before age 4 months reported awareness of guidelines about infant feeding; for these parents, major reasons offered for early introduction were the child was dissatisfied with only receiving formula or breast milk or the child slept better at night when consuming solids [30].

Recommendations from the AAP and Bright Futures were developed to help pediatric clinicians inform parents about the timing of starting solid foods. Several studies on other infant feeding practices in clinical or regional samples of parents suggest provider discussion may have little or no influence on parent feeding practices [31-33]. Based on the results of this study and earlier research, it appears anticipatory guidance by physicians is having little effect on promoting optimal feeding behavior among all parents. Our study shows nearly all parents of young children ages 4 months and older have discussed the introduction of solids with their pediatric provider. Having a discussion is not the issue, but the effectiveness on promoting optimal parent infant feeding behaviors is questionable. Our findings bolster those of prior studies that parental awareness of recommendations is not sufficient. Heinig (2006) suggests mothers believe providers would not understand if they rejected infant feeding recommendations; therefore, mothers chose not to ask providers for assistance when facing difficulties and relied on relatives for guidance on infant feeding [32].

With such a high proportion of provider discussion related to food and feeding, this study lacks power to detect effects of provider discussion. These high rates of reported provider discussion of introduction of solids among parents of infants ages 4-9 months do suggest that any differences worthy of study may be associated with the effectiveness and quality of the information provided rather than if the topic was raised with the parent. Rather than encouraging more pediatric clinicians to discuss the timing of solid foods introduction, efforts might be better spent on improving the effectiveness of communicating the clinicians messages to parents and perhaps on bolstering this educational message to parents outside of clinical settings (i.e., through WIC). Another consideration is guidelines for pediatric well-child visits compiled in the Bright Futures guidelines advise pediatricians to discuss the concept of introducing solid foods at the 4-month well-child visit [16]. Our findings suggest nearly $20 \%$ of parents have already introduced solid foods by this visit, suggesting the discussion may need to occur earlier with parents.

Several limitations should be noted. Our study used parent reports and recall to establish the timing of solid foods introduction. While this is a similar methodology to many studies of this topic, typical limitations of recallbased studies apply to this work. NSECH data were collected nearly 10 years ago, although there are no more recent national datasets focusing on children under 3 years of age that could provide updated information on these research questions.

In conclusion, more optimal timing of introducing solids might be achieved by bolstering messages for mothers who are not breastfeeding. Single-headed households are more likely to introduce solids early and mothers with low education more likely to introduce solids late. Although income is not an independent risk factor for early initiation, having more than high school education appears protective for introducing within the target window. As a result, WIC participants are likely a good target given overall lower educational levels for mothers receiving these benefits and the high WIC participation rate among single-headed eligible households. Our findings also suggest pediatric practices should particularly emphasize the recommended timing of introducing solids for mothers who are not breastfeeding, and discussion about the introduction of solid food should take place at the 2 month well child visit. In addition, the association of longer breastfeeding duration and optimal timing of solid introduction illustrates another positive association with optimal breastfeeding practices and emphasizes the importance of supporting breastfeeding families to meet the $\mathrm{WHO}$ and AAP recommendations $[1,13]$.

Acknowledgments The authors would like to acknowledge Bill Sribney for his statistical expertise and contribution and Pamela Hong for her assistance with manuscript preparation.

Open Access This article is distributed under the terms of the Creative Commons Attribution Noncommercial License which permits any noncommercial use, distribution, and reproduction in any medium, provided the original author(s) and source are credited.

\section{References}

1. World Health Organization. (2002). Infant and child nutrition: Global strategy for infant and young child feeding.

2. Kramer, M., \& Kakuma, R. (2002). The optimal duration of exclusive breastfeeding: a systematic review. Cochrane Database 
of Systematic Reviews 2002, Issue 1. Art. No.: CD003517. DOI: 10.1002/14651858.CD003517.

3. World Health Organization. (1998). Complementary feeding of young children in developing countries: a review of current scientific knowledge.

4. Dewey, K. (2001). Guiding principles for complementary feeding of the breastfed child. 2001 WHO. URL: http://www.who.int/ nutrition/publications/guiding_principles_compfeeding_breastfed. pdf.

5. Arenz, S., \& von Kries, R. (2005). Protective effect of breastfeeding against obesity in childhood: Can a meta-analysis of observational studies help to validate the hypothesis? Advances in Experimental Medicine and Biology, 569, 40-48.

6. Canadian Pediatric Society. (1998). Nutrition for healthy term infants. In: Ottowa Minister of Public Works and Government Services.

7. Norris, J. M., Barriga, K., Klingensmith, G., Hoffman, M., Eisenbarth, G. S., Erlich, H. A., et al. (2003). Timing of initial cereal exposure in infancy and risk of islet autoimmunity. The Journal of the American Medical Association, 290(13), 1713-1720.

8. Tarini, B., Carroll, A., Sox, C., \& Christakis, D. (2006). Systematic review of the relationship between early introduction of solid foods to infants and the development of allergic disease. Archives of Pediatrics and Adolescent Medicine, 160, 502-507.

9. Butte, N. F., Lopez-Alarcon, M. G., \& Garza, C. (2002). Nutrient adequacy of exclusive breastfeeding for the term infant during the frist six months of life. WHO.

10. Kramer, M. S., Chalmers, B., Hodnett, E. D., Sevkovskaya, Z., Dzikovich, I., Shapiro, S., et al. (2001). Promotion of breastfeeding intervention trial (PROBIT): A randomized trial in the Republic of Belarus. The Journal of the American Medical Association, 285, 413-420.

11. Gluckman, P. D., Hanson, M. A., Bateson, P., Beedle, A. S., Law, C. M., Butta, Z. A., et al. (2009). Towards a new developmental synthesis: Adaptive developmental plasticity and human disease. Lancet, 373, 1654-1657.

12. Cottrell, E. C., \& Ozanne, S. E. (2008). Early life programming of obesity and metabolic disease. Physiology \& Behavior, 94, $17-28$.

13. American Academy of Pediatrics Section on Breastfeeding. (2005). Breastfeeding and the use of human milk. Pediatrics. 2005; 115(2): 496-506. URL: http://pediatrics.aapublications.org/ cgi/content/full/115/2/496.

14. Kleinman, R. (2009). Complementary feeding. Pediatric nutrition handbook. American Academy of Pediatrics. (6):113-144.

15. Food and Nutrition Service. (2009). Women, infants, and children fact sheet. 2009 April. URL: http://www.fns.usda.gov/wic/WICFact-Sheet.pdf.

16. Richards, J., Anastasi, J., \& Clark, E. (2006). Well-child care: A Bright futures curriculum for providers in $\mathrm{MCH} \&$ Medicaid/ EPSDT Settings. URL: http://www.brightfutures.org/wellchild. html.

17. Schuster, M. A., Duan, N., Regalado, M., \& Klein, D. J. (2000). What information do parents receive? What information do they want? Archives of Pediatrics and Adolescent Medicine, 154, 1191-1198.

18. WHO Multicentre Growth Reference Study Group. (2006) Complementary feeding in the WHO Multicentre growth reference study. Acta Paediatrica (450): 27-37.

19. Alder, E. M., Williams, F. L., Anderson, A. S., Forsyth, S., Florey Cdu, V., \& van der Velde, P. (2004). What influences the timing of the introduction of solid food to infants? British Journal of Nutrition, 92(3), 527-531.

20. Hediger, M. L., Overpeck, M. D., Ruan, W. J., \& Troendle, J. F. (2000). Early infant feeding and growth status of US-born infants and children aged 4-71 months: Analyses from the third National Health and Nutrition Examination Survey, 1988-1994. American Journal of Clinical Nutrition, 72, 159-167.

21. Hendricks, K., Briefel, R., Novak, T., \& Ziegler, P. (2006). Maternal and child characteristics associated with infant and toddler feeding practices. Journal of the American Dietetic Association, 106(1 suppl 1), S135-S148.

22. Blumberg, S. J., Halfon, N., \& Olson, L. M. (2004). The national survey of early childhood health. Pediatrics, 113(6), 1899-1906.

23. Rao, J. N. K., \& Scott, A. J. (1984). On chi-squared tests for multiway contingency tables with cell proportions estimated from survey data. Annals of Statistics, 12, 46-60.

24. Rao, J. N. K., \& Thomas, D. R. (1989). Chi-squared tests for contingency tables. In C. Skinner, D. Holt, \& T. M. F. Smith (Eds.), Analysis of Complex Surveys. New York: John Wiley \& Sons.

25. Korn, E. G., \& Graubard, B. I. (1990). Simultaneous testing of regression coefficients with complex survey data: Use of Bonferroni t-statistics. The American Statistician, 44, 270-276.

26. StataCorp. (2004). Stata statistical software release 8.2. In. College station, TX: Stata corporation.

27. Ogden, C. L., Carroll, M. D., Curtain, L. R., McDowell, M. A., Tabak, C. J., \& Flegal, K. M. (2006). Prevalence of overweight and obesity in the United States, 1999-2004. The Journal of the American Medical Association, 295, 1549-1555.

28. Bronner, Y. L., Gross, S. M., Caulfield, L., Bentley, M. E., Kessler, L., Jensen, J., et al. (1999). Early introduction of solid foods among urban African-American participants in WIC. Journal of the American Dietetic Association, 99(4), 457-461.

29. Libbus, M. K., \& Kolostov, L. S. (1994). Perceptions of breastfeeding and infant feeding choice in a group of low-income midMissouri women. Journal of Human Lactation, 10(1), 17-23.

30. Crocetti, M., Dudas, R., \& Krugman, S. (2004). Parental beliefs and practices regarding early introduction of solid foods to their children. Clinical Pediatrics, 43, 541.

31. Barton, S. J. (2001). Infant feeding practices of low-income rural mothers. The American Journal of Maternal Child Nursing, 26(2), 93-97.

32. Heinig, M. J., Follett, J. R., Ishii, K. D., Kavanagh-Prochaska, K., Cohen, R., \& Panchula, J. (2006). Barriers to compliance with infant-feeding recommendations among low-income women. Journal of Human Lactation, 22(1), 27-38.

33. Wright, A. L., Holberg, C., \& Taussig, L. M. (1988). Infantfeeding practices among middle-class Anglos and Hispanics. Pediatrics, 82((3 pt 2)), 496-503. 